\title{
Article \\ Overcoming Strength-Ductility Trade-Off at Cryogenic Temperature of Low Carbon Low Alloy Steel via Controlling Retained Austenite Stability
}

\author{
Xuelin Wang ${ }^{1}$, Zhenjia Xie ${ }^{1, * \mathbb{C}}$, Chengjia Shang ${ }^{1, *}$ and Gang Han ${ }^{2}$ \\ 1 Collaborative Innovation Center of Steel Technology, University of Science and Technology Beijing, \\ Beijing 100083, China; xuelin2076@ustb.edu.cn \\ 2 Institute of Advanced Materials and Technology, University of Science and Technology Beijing, \\ Beijing 100083, China; hangang@mater.ustb.edu.cn \\ * Correspondence: zjxie@ustb.edu.cn (Z.X.); cjshang@ustb.edu.cn (C.S.)
}

check for updates

Citation: Wang, X.; Xie, Z.; Shang, C.;

Han, G. Overcoming

Strength-Ductility Trade-Off at Cryogenic Temperature of Low Carbon Low Alloy Steel via Controlling Retained Austenite Stability. Metals 2021, 11, 157. https://doi.org/10.3390/met110 10157

Received: 4 December 2020

Accepted: 12 January 2021

Published: 15 January 2021

Publisher's Note: MDPI stays neutral with regard to jurisdictional claims in published maps and institutional affiliations.

Copyright: (c) 2021 by the authors. Licensee MDPI, Basel, Switzerland. This article is an open access article distributed under the terms and conditions of the Creative Commons Attribution (CC BY) license (https:/ / creativecommons.org/licenses/by/ $4.0 /)$.

\begin{abstract}
Stress-strain behavior of a low carbon low alloy multiphase steel with ferrite, tempered bainite, and retained austenite was studied at different cryogenic temperatures. Results indicated that both strength and ductility were enhanced with decreasing tensile testing temperature. The enhancement of both strength and ductility was attributed to the decreased mechanical stability of retained austenite with decreasing temperature, resulting in sufficient transformation induced plasticity (TRIP) effect for increasing work hardening rate.
\end{abstract}

Keywords: multiphase steel; retained austenite stability; work hardening rate; ductility; low temperature property

\section{Introduction}

High strength low alloy (HSLA) steels have attracted great interest for wide fields of applications, due to their excellent strength-toughness balance, economy, and weldability [1-3]. With applied fields of HSLA steels extending to low temperature environment, low temperature toughness is of significant importance in consideration of safety. Generally, yield strength of HSLA steels increases dramatically to be higher than fracture strength with decreasing temperature, thus sudden brittle fracture takes place without ductile plastic deformation [4]. This strength-ductility trade-off greatly limits their application in low temperature environments. Therefore, it is very important to simultaneously enhance yield strength and impact toughness with decreasing temperature for HSLA steels by tailoring microstructure. Recently, it has been suggested that the strength-ductility trade-off can be overcome though the controlled deformation-induced martensitic transformation from face-centered cubic to body-centered cubic via metastability engineering in CoCrFeNiMo medium-entropy alloys [5]. The purpose of this work is to introduce multiphase microstructure containing retained austenite to a low carbon low alloy steel for enhancing the work hardening ability at low temperatures, resulting in high fracture strength and high ductility.

A lot of efforts have been devoted to improving strength, ductility, and toughness of HSLA steels by tailoring microstructure, and progress has been made. It has revealed that refinement of prior austenite grains via increasing high angle grain boundaries (HAGBs) is helpful for decreasing ductile-to-brittle transition temperature (DBTT), because HAGBs can retard brittle crack propagation [6,7]. Control of multiphase microstructure via producing metastable retained austenite in low carbon low alloy steels was able to significantly improve ductility and low temperature toughness [2,8-11]. Metastable retained austenite was suggested to afford TRIP effect during tensile or impact to enhance the plastic deformation ability before fracture. The stability of retained austenite is crucial to performance in service [12,13]. The main concern is that once retained austenite in the steel is unstable and transforms into martensite thermally or mechanically due to a small deformation in 
low temperature service, sudden brittle fracture takes place, resulting in disaster. Hence, the objectives of the present work are to study the stability of retained austenite in a low carbon low alloy multiphase steel produced by the two-step intercritical heat treatment, and to elucidate the effect of retained austenite stability on stress-strain behavior at cryogenic temperature.

\section{Material and Methods of Experiments}

The chemical composition of the experimental steel was Fe-0.07C-0.36Si-1.78Mn$0.51 \mathrm{Ni}-0.3 \mathrm{Mo}-0.78 \mathrm{Nb}-0.02 \mathrm{Ti}$ in weight percent $(\mathrm{wt} \%)$. The steel was melted in vacuum induction furnace and cast into ingot of weight $25 \mathrm{~kg}$. The ingot was reheated to $1200{ }^{\circ} \mathrm{C}$ and held for $2 \mathrm{~h}$, then forged into rods with diameter of $16 \mathrm{~mm}$, and air cooled to ambient temperature. The forged rods were intercritically annealed at $740{ }^{\circ} \mathrm{C}$ for $30 \mathrm{~min}$, subsequently air cooled to ambient temperature. Next, the annealed specimen was tempered at $680^{\circ} \mathrm{C}$ for $30 \mathrm{~min}$, and finally air cooled to ambient temperature. Mechanical properties in terms of strength and elongation of the treated samples ( $\varphi 5 \mathrm{~mm}$ standard tensile test samples) were measured at an extension rate of $2.5 \times 10^{-3} \mathrm{~s}^{-1}$ with an extensometer of $25 \mathrm{~mm}$ at cryogenic temperatures of $-80,-120,-160$, and $-196{ }^{\circ} \mathrm{C}$, respectively. The reason why the tensile test starts at $-80^{\circ} \mathrm{C}$ is that the material has excellent room temperature properties and good low temperature toughness [8]. The model of cryogenic tensile testing machine is SANS CMT5000. The specimen was cooled to the set temperature with liquid helium (he), then kept for $10 \mathrm{~min}$, and then tensile test was carried out, as shown in Figure 1.

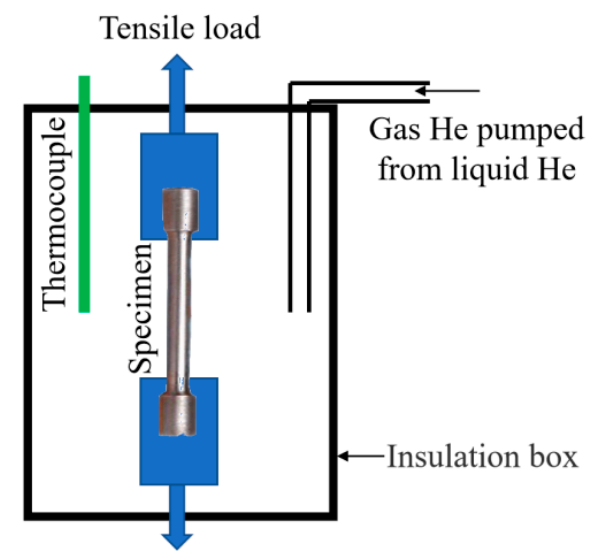

Figure 1. Schematic diagram of cryogenic tensile test process.

Heat treated samples were mechanically polished and etched with $4 \%$ nital using standard metallographic procedures for TESCAN MIRA3 field emission scanning electron microscopy (SEM, TESCAN, Brno, Czech Republic). To obtain information on distribution and morphology of retained austenite, electron backscatter diffraction (EBSD, Oxford Instruments, Oxford, UK) analysis was carried out after mechanical and electrolytic polishing using TESCAN MIRA3 field emission scanning electron microscope (FE-SEM, TESCAN, Brno, Czech Republic) at an acceleration voltage of $20 \mathrm{kV}$, with a step size of $60 \mathrm{~nm}$. EBSD data was post-processed by HKL CHANNEL 5 flamenco software (Oxford Instruments, Oxford, UK) to acquire necessary information. The amount of retained austenite was also evaluated using magnetic measurements [14]. For these measurements, samples were cut with approximately $150 \mathrm{mg}$. The $\mathrm{M}(\mathrm{H})$ curves were obtained at $300 \mathrm{~K}$ using a PPMS (Physical Property Measurement System, Quantum Design, San Diego, USA). The hysteresis loops were carried out using the following sweep rates: $0.4 \mathrm{kOe} / \mathrm{min}$ for $|H|<0.5 \mathrm{kOe}$, $1.8 \mathrm{kOe} / \mathrm{min}$ for $0.5<|H|<5 \mathrm{kOe}$ and $10 \mathrm{kOe} / \mathrm{min}$ for $6<|H|<15 \mathrm{kOe}$. 


\section{Results and Discussion}

Representative SEM micrograph of the heat-treated sample is given in Figure 2a. Multiphase microstructure consisting of ferrite, tempered bainite (TB), and retained austenite (RA) was obtained. Polygonal ferrite $(\mathrm{PF})$ with diameter of $\approx 10 \mu \mathrm{m}$ was observed along prior austenite grain boundary. Lath tempered bainite (TB, tempered at $\left.680{ }^{\circ} \mathrm{C}\right)$ and intercritical ferrite composited as lamellar structure. The distribution and morphology of retained austenite are presented by EBSD image in Figure 2b. It was seen that retained austenite distributed mainly in the lamellar structure with fine blocky and thin film-like morphologies. The stabilization of retained austenite as a result of two-step heat treatment was reported in our previous work $[8,15]$.

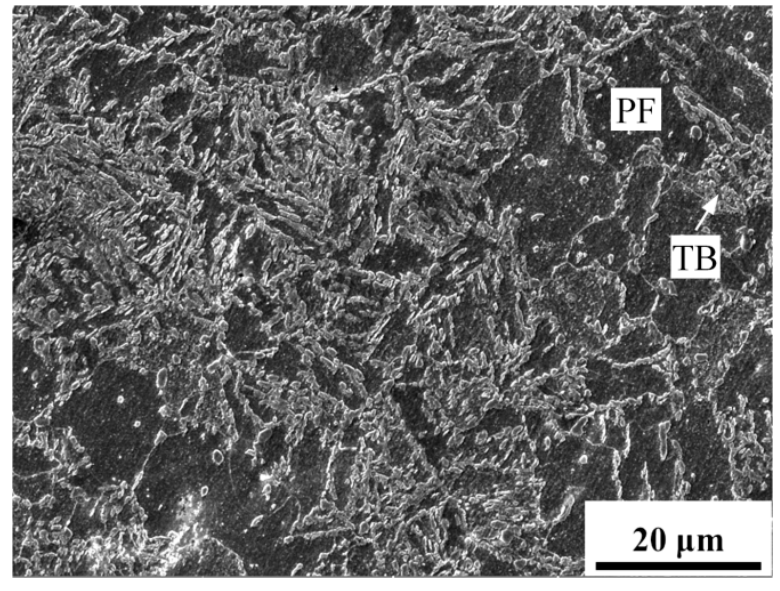

(a)

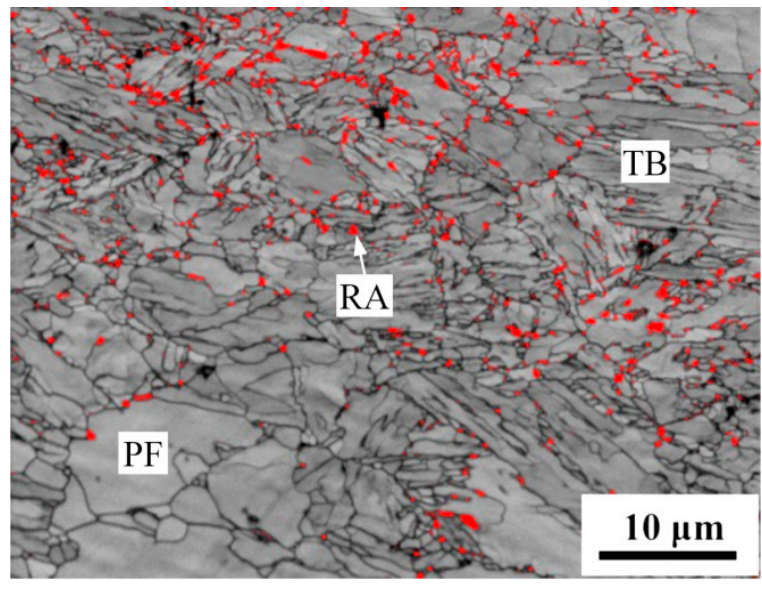

(b)

Figure 2. (a) SEM micrograph showing multiphase microstructure and (b) EBSD image showing morphology and distribution of retained austenite (RA) in the multiphase microstructure of the studied steel, in which red areas represent retained austenite. (PF: polygonal ferrite, TB: tempered bainite).

Figure 3a shows the engineering stress-stain curves of the studied steel measured at temperatures of $-80,-120,-160$, and $-196^{\circ} \mathrm{C}$. It was found that both yield strength and tensile strength were increased with decreasing tensile temperature. The yield strength and tensile strength were 507 and $805 \mathrm{MPa}$ at $-80^{\circ} \mathrm{C}$, respectively. When the test temperature was decreasing to $-196^{\circ} \mathrm{C}$, the yield strength and tensile strength were increased to 846 and $1083 \mathrm{MPa}$, respectively. More importantly, the uniform and total elongations also presented a trend to increase with decreasing the tensile temperature, except that there was a slight decrease of total elongation at $-160{ }^{\circ} \mathrm{C}$. The studied steel exhibited high uniform elongation of $16.1-19.1 \%$ and high total elongation of $30.0-33.3 \%$ at tensile temperature range of -80 to $-196^{\circ} \mathrm{C}$. This atypical phenomenon of stress-strain behavior in this work may be ascribed to the presence of the TRIP effect of retained austenite, rather than the classical deformation mechanism by dislocation glide and dislocation interactions $[16,17]$.

To understand the ductility of the studied steel at low temperatures, work hardening behavior at examined temperatures was studied. The work hardening rates are plotted in Figure $3 b$, according to the calculation results from the Hollomon equation $[18,19]$. Three-stage work hardening behavior was characterized for samples tensile tested at all temperatures, namely the work hardening rate firstly decreased, then increased, and finally decreased to failure with increasing strain, as observed in TRIP-aided steels at room temperature [20,21]. It can be found that the decrease of work hardening rate in the first stage was stopped at the end of the yield plateau for all four testing temperatures. This suggested that the first stage of work hardening behavior was dominated by dislocation glide in ferrite due to breaking away from Cottrell atmosphere. The increase in the second stage was ascribed to the TRIP effect of retained austenite [21]. In the third stage, the downtrend of work hardening rate became slow, leading to delaying the occurrence of 
necking and enhancing the ductility. This indicated that retained austenite manifested variations in mechanical stability under different loading temperatures. At relative high temperature of $-80^{\circ} \mathrm{C}$, some of the retained austenite had high mechanical stability, they were stable to supply the TRIP effect till failure. With decreasing tensile testing temperature, the mechanical stability of retained austenite decreased, such that more retained austenite afforded the TRIP effect during strain to provide sustainable work hardening rate. This was the reason for the atypical phenomenon of increase in ductility with decreasing temperature.

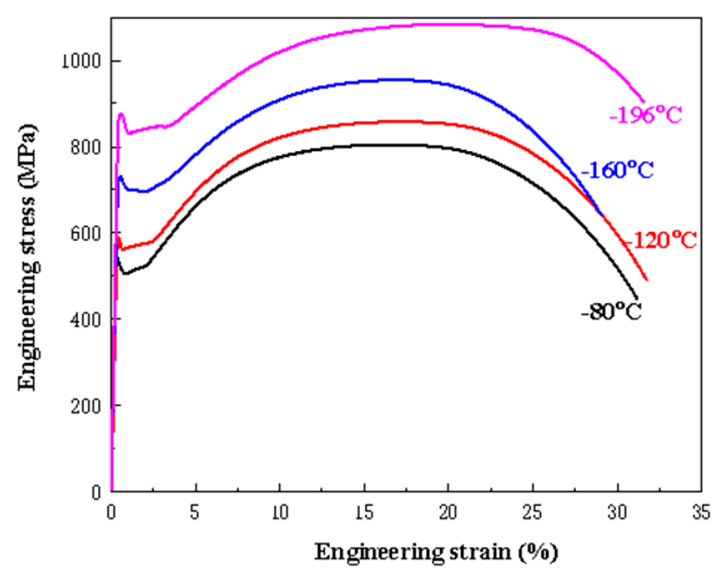

(a)

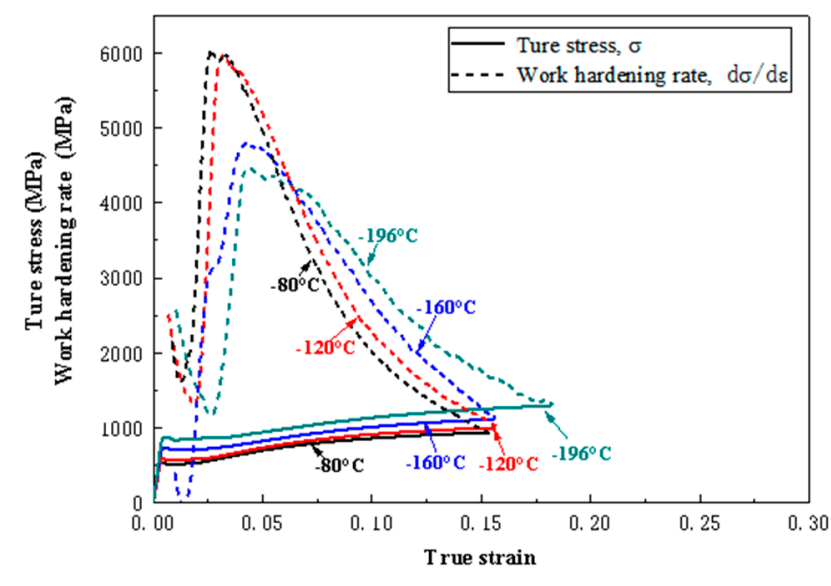

(b)

Figure 3. (a) Engineering stress-strain curves and (b) true stress-strain curves and work hardening rate of the studied steel at low temperatures.

To study thermal and mechanical stability of retained austenite, the volume fraction of retained austenite was determined by saturation magnetization $\left(M_{s}\right)$ for the undeformed and uniform deformed area of samples after testing at different temperatures. The obtained magnetization $(M)$ curves as a function of applied magnetic field $(H)$ are shown in Figure 4. It can be seen that the $M_{S}$ was identical for samples without strain at different temperatures. This indicated that retained austenite in the studied steel had high thermal stability in temperature range of -80 to $-196^{\circ} \mathrm{C}$. After the maximum uniform deformation, the $M_{s}$ increased obviously. There was a tendency that the increment of $M_{s}$ increased with decreasing testing temperature. This effect was attributed to the decreasing of non-ferromagnetic phase of retained austenite. Hence, it can be concluded that the mechanical stability of retained austenite in the studied steel decreased with decreasing temperature. Therefore, more retained austenite transformed to martensite during strain, resulting in sustainable work hardening rate due to sufficient TRIP effect. Given that all retained austenite transformed to martensite at $-196{ }^{\circ} \mathrm{C}$, the $M_{s}$ at $-196{ }^{\circ} \mathrm{C}$ was taken as $M_{s}(f)$ for the austenite-free sample. Therefore, based on the calculation method in [14], the value of the last point of the magnetization curves $\left(M_{s}(c)\right)$ obtained at different conditions is used to calculate the volume fraction of retained austenite $\left(f_{\gamma}\right)$. The calculation method is presented in Equation (1).

$$
f_{\gamma}=\frac{M_{s}(f)-M_{s}(c)}{M_{s}(f)} \times 100 \%
$$

Thus, the volume fraction of retained austenite can be calculated as $\approx 21.1 \%$ for samples undeformed at -80 to $-196{ }^{\circ} \mathrm{C}$. After maximum uniform deformation at -80 and $-120^{\circ} \mathrm{C}$, the volume fraction of retained austenite was $\approx 4.5-5.2 \%$. When the testing temperature decreased to $-160{ }^{\circ} \mathrm{C}$, the volume fraction of retained austenite decreased to $\approx 1.8 \%$. This confirmed that the enhancement of both strength and ductility with decreasing temperature was ascribed to the decreased mechanical stability of retained austenite, resulting in sufficient transformation induced plasticity (TRIP) effect for sustainable work 
hardening rate. The main reason why retained austenite can be stable to low temperature $\left(-196^{\circ} \mathrm{C}\right)$ is ascribed to the highly enrichment of Mn and C during the two-step intercritical heat treatment. Atom probe tomography analysis in our previous studies revealed that the $\mathrm{Mn}$ and $\mathrm{C}$ contents were $\approx 6.6$ and $0.4 \mathrm{wt} \%$. In addition, the obtained retained austenite was very fine, the average size was $\approx 300 \mathrm{~nm}$ in diameter. Hence, the retained austenite was very stable thermally up to $-196{ }^{\circ} \mathrm{C}[8,15]$.

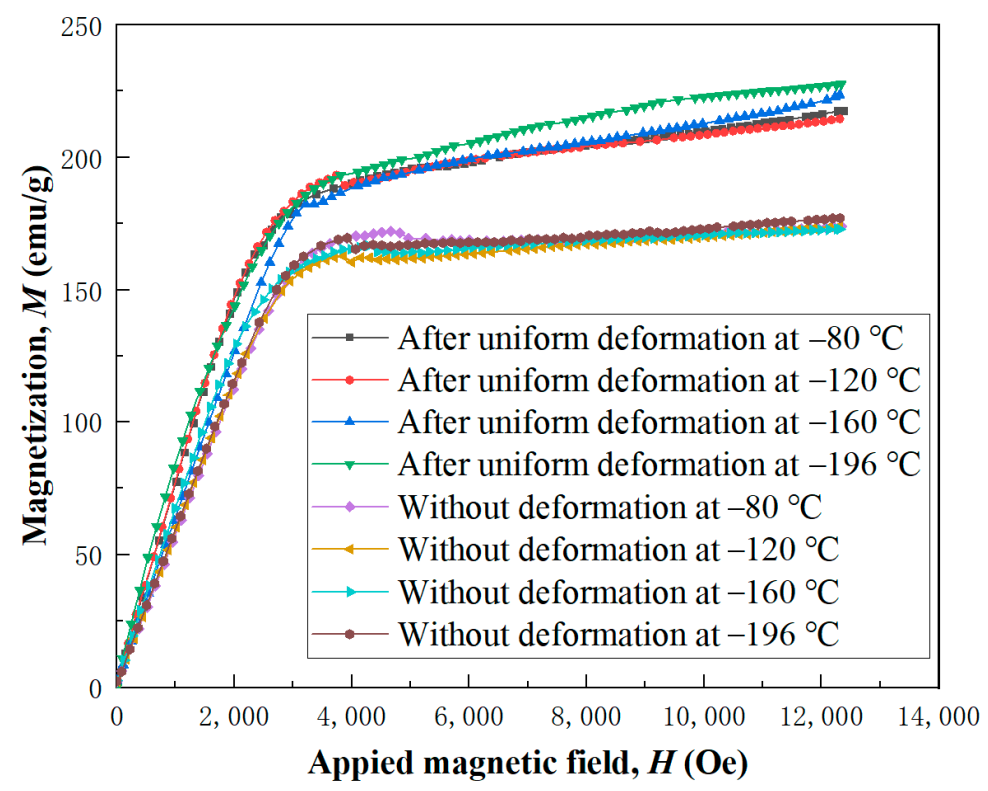

Figure 4. Magnetization $(M)$ curves as a function of applied magnetic field $(H)$ for samples without deformation and after uniform deformation in the range of -80 to $-196{ }^{\circ} \mathrm{C}$.

To reveal the failure mechanisms at different testing temperatures, the fracture surfaces were examined using SEM. The macroscopic and microscopic fractographs are shown in Figures 5 and 6 . It can be seen from the Figure 5 that with the decrease of temperature, the anisotropic fracture morphology gradually changes to the isotropic fracture morphology. When the temperature decreases to $-196{ }^{\circ} \mathrm{C}$, the fracture surface presents complete brittleness. This phenomenon can be attributed to the change of microstructure with the decrease of temperature and the conditions of testing. From Figure 6, it can be seen that several main cracks with edge step were always observed along the diameter direction. Full ductile fracture with dimples was characterized for samples tensile tested at -80 and $-120^{\circ} \mathrm{C}$. Based on our previous study, this effect could be caused by comprehensive influence of texture evolution, the redistribution of grain boundaries, and the state of three-dimensional stress with large tensile plastic deformation during necking [22]. When testing temperature decreased to -160 and $-196{ }^{\circ} \mathrm{C}$, the main crack was not obvious, and some small cracks and brittle fracture were observed within the matrix. This indicated that after large uniform deformation, the plasticity during necking decreased at $-196^{\circ} \mathrm{C}$. This may ascribe to the full consumption of retained austenite during uniform deformation. Therefore, without the help of TRIP effect from retained austenite to release the stress, the brittle fracture occurred during necking. This result suggested that some stable retained austenite that remained after uniform deformation could suppress brittle collapse and ensure safety in service. 


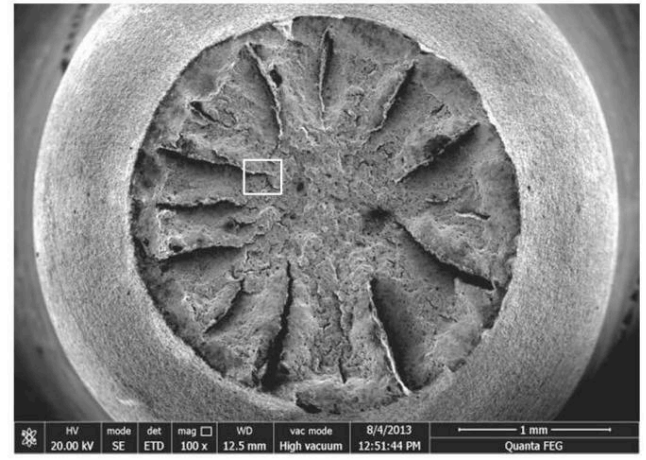

(a)

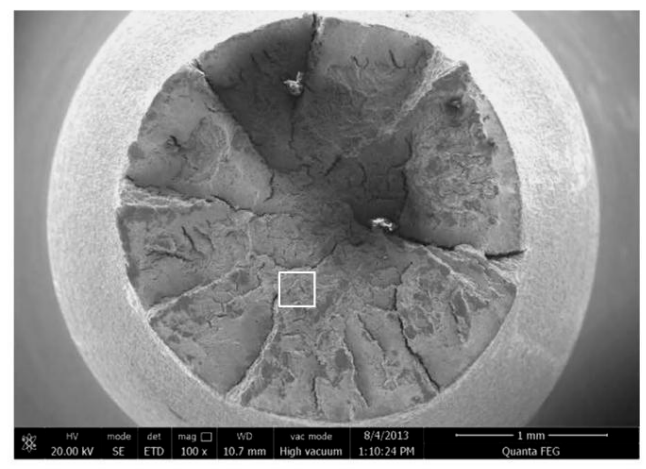

(c)

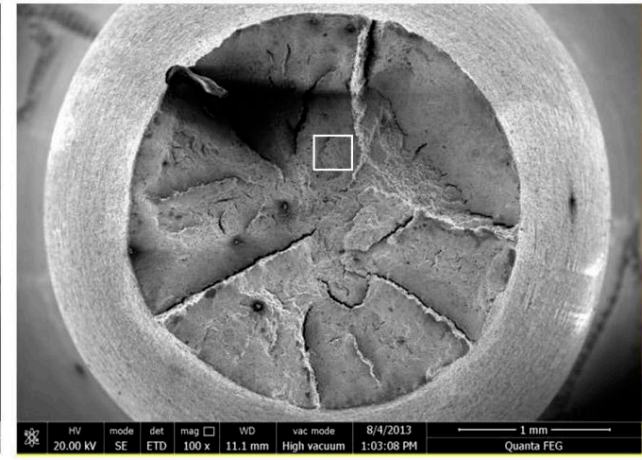

(b)

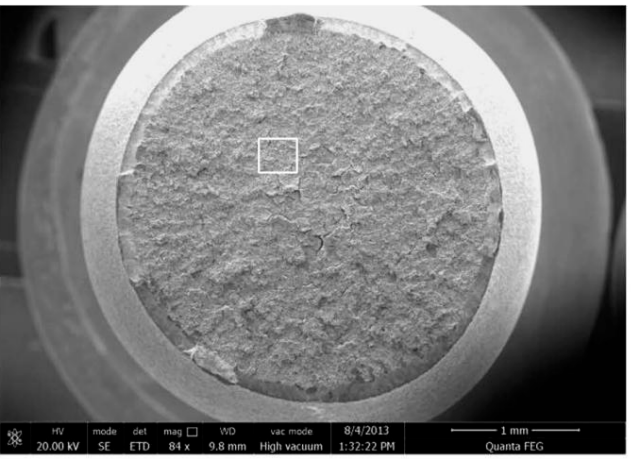

(d)

Figure 5. SEM images showing the macroscopic fractographs of samples tested at different temperatures: $(\mathbf{a})-80{ }^{\circ} \mathrm{C}$, (b) $-120^{\circ} \mathrm{C},(\mathbf{c})-160{ }^{\circ} \mathrm{C}$, and (d) $-196^{\circ} \mathrm{C}$.
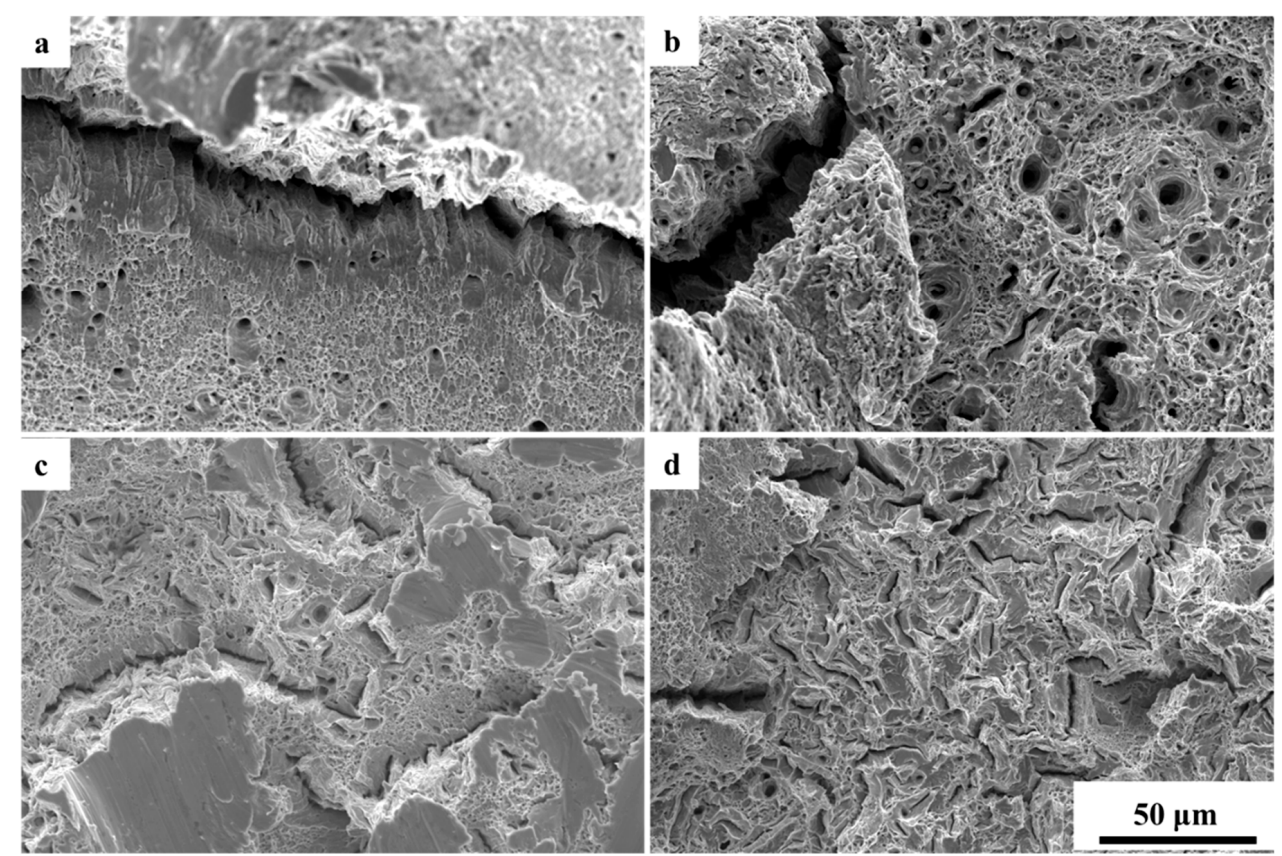

Figure 6. SEM images showing the microscopic fractographs of samples tested at different temperatures: (a) $-80{ }^{\circ} \mathrm{C}$, (b) $-120^{\circ} \mathrm{C},(\mathbf{c})-160^{\circ} \mathrm{C}$, and (d) $-196^{\circ} \mathrm{C}$, corresponding to the marked area in Figure 5 . 


\section{Conclusions}

The stability of retained austenite was studied in a low carbon low alloy steel processed by the two-step intercritical heat treatment. The retained austenite exhibited high thermal stability in range of -80 to $-196^{\circ} \mathrm{C}$. Whereas, mechanical stability decreased with decreasing temperature from -80 to $-196^{\circ} \mathrm{C}$. The decrease in mechanical stability of retained austenite was helpful for enhancing the uniform elongation via sufficient TRIP effect during uniform deformation, resulting in simultaneous enhancement of strength and ductility at low temperatures. However, the full consumption of retained austenite during uniform strain may raise risk of sudden brittle collapse during necking.

Author Contributions: X.W. contributed primarily to the writing and compilation of manuscript and data analysis; Z.X. was heavily involved in the project conceptualization, administration, and planning; C.S. was in charge of reviewing and editing the manuscript; G.H. contributed primarily to carrying out the main experiments and data collection. All authors have read and agreed to the published version of the manuscript.

Funding: This research was funded by the National Natural Science Foundation of China (No. 51701012) and the Fundamental Research Funds for Central Universities (No. FRF-TP-19-052A2).

Institutional Review Board Statement: Not applicable.

Informed Consent Statement: Not applicable.

Data Availability Statement: Data is contained within the article.

Acknowledgments: S. van der Zwaag at Delft University of Technology is acknowledged for his valuable comments and suggestions.

Conflicts of Interest: The authors declare no conflict of interest.

\section{References}

1. Sun, X.J.; Yuan, S.F.; Xie, Z.J.; Dong, L.L.; Shang, C.J.; Misra, R.D.K. Microstructure-property relationship in a high strength-high toughness combination ultra-heavy gauge offshore plate steel: The significance of multiphase microstructure. Mater. Sci. Eng. A 2017, 689, 212-219. [CrossRef]

2. Xie, Z.J.; Shang, C.J.; Wang, X.L.; Wang, X.M.; Misra, R.D.K. Recent progress in third-generation low alloy steels developed under M3 microstructure control. Int. J. Miner. Metall. Mater. 2020, 27, 1-9. [CrossRef]

3. Lee, W.B.; Hong, S.G.; Park, C.G.; Kim, K.H.; Park, S.H. Influence of Mo on precipitation hardening in hot rolled HSLA steels containing Nb. Scr. Mater. 2000, 43, 319-324. [CrossRef]

4. Morris, J.W., Jr. Stronger, tougher steels. Science 2008, 320, 1022-1023. [CrossRef]

5. Kwon, H.; Moon, J.; Bae, J.W.; Park, J.M.; Son, S.; Do, H.S.; Lee, B.J.; Kim, H.S. Precipitation-driven metastability engineering of carbon-doped CoCrFeNiMo medium-entropy alloys at cryogenic temperature. Scr. Mater. 2020, 188, 140-145. [CrossRef]

6. Gourgues, A.F. Electron backscatter diffffraction and cracking. Mater. Sci. Technol. 2002, 18, 119-133. [CrossRef]

7. Wang, X.L.; Wang, Z.Q.; Dong, L.L.; Shang, C.J.; Ma, X.P.; Subramanian, S.V. New insights into the mechanism of cooling rate on the impact toughness of coarse grained heat affected zone from the aspect of variant selection. Mater. Sci. Eng. A 2017, 704, 448-458. [CrossRef]

8. Xie, Z.J.; Yuan, S.F.; Zhou, W.H.; Yang, J.R.; Guo, H.; Shang, C.J. Stabilization of retained austenite by the two-step intercritical heat treatment and its effect on the toughness of a low alloyed steel. Mater. Des. 2014, 59, 193-198. [CrossRef]

9. Xie, Z.J.; Shang, C.J.; Zhou, W.H.; Wu, B.B. Effect of retained austenite on ductility and toughness of a low alloyed multi-phase steel. Acta Metall. Sin. 2016, 52, 224-232.

10. Han, J.; da Silva, A.K.; Ponge, D.; Raabe, D.; Lee, S.M.; Lee, Y.K.; Lee, S.I.; Hwang, B. The effects of prior austenite grain boundaries and microstructural morphology on the impact toughness of intercritically annealed medium Mn steel. Acta Mater. 2017, 122, 199-206. [CrossRef]

11. Yen, H.W.; Ooi, S.W.; Eizadjou, M.; Breen, A.; Huang, C.Y.; Bhadeshia, H.K.D.H.; Ringer, S.P. Role of stress-assisted martensite in the design of strong ultrafine-grained duplex steels. Acta Mater. 2015, 82, 100-114. [CrossRef]

12. Jimenez-Melero, E.; van Dijk, N.H.; Zhao, L.; Sietsma, J.; Offerman, S.E.; Wright, J.P.; van der Zwaag, S. Characterization of individual retained austenite grains and their stability in low-alloyed TRIP steels. Acta Mater. 2007, 55, 6713-6723. [CrossRef]

13. Blondé, R.; Jimenez-Melero, E.; Zhao, L.; Wright, J.P.; Brück, E.; van der Zwaag, S.; van Dijk, N.H. Mechanical stability of individual austenite grains in TRIP steel studied by synchrotron X-ray diffraction during tensile loading. Mater. Sci. Eng. A 2014, 618, 280-287. [CrossRef]

14. Zhao, L.; van Dijk, N.H.; Bruck, E.; Sietsma, J.; van der Zwaag, S. Magnetic and X-ray diffraction measurements for the determination of retained austenite in TRIP steels. Mater. Sci. Eng. A 2001, 313, 145-152. [CrossRef] 
15. Xie, Z.J.; Shang, C.J.; Subramanian, S.V.; Ma, X.P.; Misra, R.D.K. Atom probe tomography and numerical study of austenite stabilization in a low carbon low alloy steel processed by two-step intercritical heat treatment. Scr. Mater. 2017, 137, 36-40. [CrossRef]

16. Blondé, R.; Jimenez-Melero, E.; Zhao, L.; Wright, J.P.; Brück, E.; Van der Zwaag, S.; Van Dijk, N.H. High-energy X-ray diffraction study on the temperature-dependent mechanical stability of retained austenite in low-alloyed TRIP steels. Acta Mater. 2012, 60, 565-577. [CrossRef]

17. Curtze, S.; Kuokkala, V.T.; Hokka, M.; Peura, P. Deformation behavior of TRIP and DP steels in tension at different temperatures over a wide range of strain rates. Mater. Sci. Eng. A 2009, 507, 124-131. [CrossRef]

18. Bag, A.; Ray, K.K.; Dwarakadasa, E.S. Influence of martensite content and morphology on tensile and impact properties of high-martensite dual-phase steels. Metall. Mater. Trans. A 1999, 30, 1193-1202. [CrossRef]

19. Movaheda, P.; Kolahgar, S.; Marashi, S.P.H.; Pouranvari, M.; Parvin, N. The effect of intercritical heat treatment temperature on the tensile properties and work hardening behavior of ferrite-martensite dual phase steel sheets. Mater. Sci. Eng. A 2009, 518, 1-6. [CrossRef]

20. Tao, K.; Choo, H.; Li, H. Transformation-induced plasticity in an ultrafine-grained steel: An in situ neutron diffraction study. Appl. Phys. Lett. 2007, 90, 101911. [CrossRef]

21. Shi, J.; Sun, X.J.; Wang, M.Q.; Hui, W.J.; Dong, H.; Cao, W.Q. Enhanced work-hardening behavior and mechanical properties in ultrafine-grained steels with large-fractioned metastable austenite. Scr. Mater. 2010, 63, 815-818. [CrossRef]

22. Li, X.; Xie, Z.; Wang, X.; Wang, X.; Shang, C. Split fracture phenomenon and mechanism in tensile tests of high strength low carbon bainitic steel. Acta Metall. Sin. 2013, 49, 167-174. [CrossRef] 